\title{
ANNOTATIONS
}

\section{The Status of Sight-testing Opticians}

The question whether sight-testing by opticians should or should not be legally recognized is one with which members of the Medical Profession in this country, especially those interested in ophthalmology, are familiar. It has been brought before them more prominently, recently, by the renewed efforts of the opticians to obtain recognition by means of a bill in Parliament. The importance of the question is fully recognized by all ophthalmic surgeons, less fully by the medical profession generally, and scarcely at all by the lay public, whose welfare it most closely concerns.

The claims of the opticians, as set forth in their latest petition to the Legislature, have been given prolonged consideration by the Council of British Ophthalmologists, whose report thereon is now made public (vide p. 554).

An authoritative opinion such as emanates from this Council is opportune, and its reasoned statements in opposing the claims of the opticians, should appeal strongly to our legislators if they are again petitioned to grant State recognition to sight-testing opticians.

In their main contention the Council of British Ophthalmologists are, in our opinion, in an unassailable position. The opticians state confidently that " a qualified optician, especially when holding a Fellowship certificate of the (British Opticai) Association would recognize a case in which the eye, through disease or otherwise, could not be properly treated by glasses, and would direct the patient to an ophthalmic surgeon or medical man."

The Council maintains that no individual who has not had a full medical training can possess the skill and judgment necessary to recognize whether failure of sight is due wholly to the need of glasses, or is caused by disease in the eyeball, optic nerve or elsewhere in the body. It follows logically that anyone who, with no more than the training of an optician, undertakes to differentiate such cases, becomes a source of danger to those members of the public who apply to him for glasses.

The statement is made by the opticians in their petition that "In a very large majority of refraction cases . . . members of the public do, in fact, visit an optician rather than an ophthalmic surgeon or a medical man." This statement is undoubtedly true, and it is this action of the misguided public which the sighttesting opticians desire to encourage, that provides the lamentable 
cases, which come later under the observation of ophthalmic surgeons, of irreparable injury to sight accruing from the inability of the optician to discriminate between refractive error and disease.

The greater portion of the Council's report deals with the question at issue; appended thereto is a brief historical account of the science and art of refraction, and of the origin of spectacles.

The status of sight-testing opticians has also been discussed by the Departmental Committee of the Ministry of Health on "The Causes and Prevention of Blindness" recently in session. The report of this Committee has now been published, and mav be obtained from one of His Majesty's Stationery Offices.

\section{Nettleship Memorial Volume}

The Francis Galton Laboratory at the University of L.ondon have recently issued an important publication as a memorial to the late Edward Nettleship. The present issue deals with only a few of the diseases in which Nettleship was interested, and it is hoped that a further volume may appear later, dealing with the inheritance of colour blindness, a subject on which, as all our readers know, Nettleship did a very great amount of work. The volume issued is prefaced by an admirable memoir on Edward Nettleship by Mr.J. B. Lawford. The subjects dealt with in this part are retinitis pigmentosa and allied diseases, congenital stationary night blindness, including, of course, the well-known Nougaret family, and glioma retinae. An excellent photograph of Mr. Nettleship forms the frontispiece, and there are reproductions of Usher's ophthalmic pictures of that very rare condition, choroideremia and twenty-six plates of pedigrees of eye disease. The book will prove a valuable one to all interested in inheritance of eye disease and in Mr. Nettleship's work thereon, and we must congratulate Dr. Julia Bell and the Francis Galton Laboratory on having made this work available in such a beautiful form. It must depend on the support that this publication receives whether the work can be continued or not. Unfortunately the production of such a work, which can only have a limited sale, is costly and the price is a little on the high side. 